\title{
DAMAGE OF SHOTCRETE UNDER FREEZE-THAW LOADING
}

\author{
Jianxun CHEN ${ }^{a}$, Pengyu ZHAO ${ }^{a}$, Yanbin LUO $^{\mathrm{a}}$, Xianghui DENG ${ }^{\mathrm{a}, \mathrm{c}}$, Qin LIU ${ }^{\mathrm{b}}$ \\ ${ }^{a}$ School of Highway, Chang'an University, Middle-section of Nan'er Huan Road, 710064, Xi'an, China \\ ${ }^{b}$ School of Civil Engineering, Chang'an University, Middle-section of Nan'er Huan Road, 710064, Xi'an, China \\ ${ }^{c}$ School of Civil and Architecture Engineering, Xi' an Technological University, No. 4 North Jinhua Road, \\ 71003, Xi'an, China
}

Received 08 Jan 2016; accepted 10 May 2016

\begin{abstract}
The freeze-thaw durability of shotcrete can be improved by adding an air-entraining agent in cold areas. The main focus of this paper is to investigate the changes in the internal pore structure of $\mathrm{C} 25$ ordinary shotcrete and shotcrete mixed with a RM-YQ air-entraining agent using computed tomography (CT) scanning technique during freezethaw cycles. The macroscopic tests were conducted, including mass loss, dynamic modulus of elasticity and ultrasonic wave velocity tests. Results were compared, and the freeze-thaw durability characteristics of shotcrete mixed with the air-entraining agent were revealed. Adding an air-entraining agent could reduce the number of pores largely that ranged mainly from $0.01 \mathrm{~mm}^{2}$ to $1.00 \mathrm{~mm}^{2}$ (excluding the pores or bubbles $<0.01 \mathrm{~mm}^{2}$ because of the precision of the CT scanning system), and could therefore improve the initial pore structure of the formed shotcrete. During first few freeze-thaw cycles, just few small pores formed. After cement mortar fragmentations appeared, the number of small pores $\left(0.01 \mathrm{~mm}^{2}\right.$ to $0.50 \mathrm{~mm}^{2}$ ) in ordinary shotcrete increased significantly. The pore structure deteriorated largely. However, this could be prevented effectively by adding an air-entraining agent. Therefore, the freeze-thaw durability of shotcrete was improved.
\end{abstract}

Keywords: freeze-thaw cycles, shotcrete, air-entraining agent, computed tomography scanning, pore structure.

\section{Introduction}

In cold regions, shotcrete undergoes freeze-thaw cycles because of the alternating changes in negative and positive temperatures. Consequently, the internal structure of shotcrete is damaged. Such an effect can threaten the stability and safety of the initial support and even the whole tunnel structure. However, a large number of evenly distributed, stable, and tiny closed bubbles can be created in the shotcrete, when an air-entraining agent is added. These bubbles are mostly spherical and uniform, with a diameter ranging from 20 and $150 \mu \mathrm{m}$ on the whole (Chen et al. 2014). Such bubbles in concrete materials can cut the channel of capillaries and therefore prevent the migration of unfrozen water caused by the frost heave force. Thus, the bubbles function as impounding reservoirs in buffering and decompression to reduce the freeze-thaw damage to concrete structures (Chatterji 2003; Lomboy, Wang 2009). Currently, an air-entraining agent has been introduced to tunnel construction in cold environments, and engineering practice has shown that the addition of such agent can significantly improve the freeze-thaw durability of shotcrete. Nevertheless, current studies have rarely investigated the mechanism of freeze-thaw damage to shotcrete mixed with an air-entraining agent. Many studies have focused on the common casting structures of concrete, such as house buildings, bridges and dams. In the present study, changes in the inner pore structure of shotcrete under freeze-thaw loading are considered as the foundation to analyze and reveal the mechanism of an air-entraining agent for improving the freeze-thaw durability of shotcrete.

Nondestructive detecting technologies, including the acoustic emission (AE) method (Suzuki et al. 2007), the ultrasonic imaging method (Molero et al. 2012; Ranz et al. 2014) and the computed tomography (CT) scanning, have been applied to investigate the internal microstructure of concrete. Among these methods, CT scanning technique is widely used, because it can obtain visualised and accurate results. Suzuki et al. (2010) used an $\mathrm{X}$-ray CT method to investigate the crack distributions in concrete-core samples obtained from reinforced concrete in an existing canal. Desirable results were obtained. Yi et al. (2015) investigated the crack growth in non-reinforced and fibre-reinforced cemented paste backfill in the unconfined compressive strength test through X-ray computed tomography to reveal the mechanism of the internal failure. Yuan et al. (2016) investigated the vari-

Corresponding author: Yanbin Luo

E-mail:lybzx2008@126.com 
ation of concrete pores and process of concrete damage under the coupled actions of sulfate attack and dryingwetting cycles depending on X-ray CT images. In addition, the images captured through the CT scanning system can also be converted into numerical concrete models or 3D images by some image analysis software, in order to investigate and analyse the internal structure of cementitious materials more quantitatively and visually (Zofka et al. 2014; Savaş 2014; Chung et al. 2015). Therefore, CT scanning technique is an effective tool to investigate changes in the internal structure of concrete materials.

In the present study, $\mathrm{C} 25$ shotcrete was selected as the test object. On the basis of the results of previous studies, the CT scanning technique was applied to investigate the changes in the internal pore structure of shotcrete mixed with an air-entraining agent and ordinary shotcrete during freeze-thaw cycles. Mass loss, dynamic modulus of elasticity and ultrasonic wave velocity tests (Chen et al. 2014) were performed to verify and supplement the CT scanning results. The test results were analysed and compared to determine the freeze-thaw durability characteristics of shotcrete mixed with an air-entraining agent.

\section{Experiment}

\subsection{Experimental materials and specimen}

The $\mathrm{C} 25$ shotcrete used in the experiment was a mixture of ordinary Portland cement (strength grade: P.042.5), clean river sand (fineness modulus: 2.72), good-grade crushed aggregates (particle size range: $5-10 \mathrm{~mm}$ ) and water. The mixture mass ratio was 1.00:2.16:1.91:0.50, which was in accordance with the recommendations of Common Portland Concrete (GB175-2007) and Technical Specification for Construction of Highway Bridge and Culvert (JTG/TF50-2011). The admixture of the shotcrete included a MRT accelerating agent (alkali-free) and a RM-YQ air-entraining agent (mainly composed of modified rosin pyrolytic polymer and high-performance anionic surfactant), which accounted for $4.0 \mathrm{wt} \%$ and $0.1 \mathrm{wt} \%$ of the cement, respectively.

The wet-mix method is commonly used to construct shotcrete in tunnels. Therefore, the wet-mix method was applied in this study to construct the test shotcrete and simulate actual engineering practice. The process of the wet-mix method was as follows. Firstly, about $30 \%$ of the total water consumption was added to the mixture of sand and aggregates, after which they were stirred fully. Secondly, the cement was placed into the mixture and stirred. Lastly, about $70 \%$ of the total water consumption was added, and all the materials were mixed and stirred before spraying. The necessary shotcrete block was produced in accordance with the requirements of the large-board spraying method (Fig. 1), as indicated in the Specification for bolt-shotcrete support (GB/T 50086-2001). The specimens were completed by cutting the hardened shotcrete.

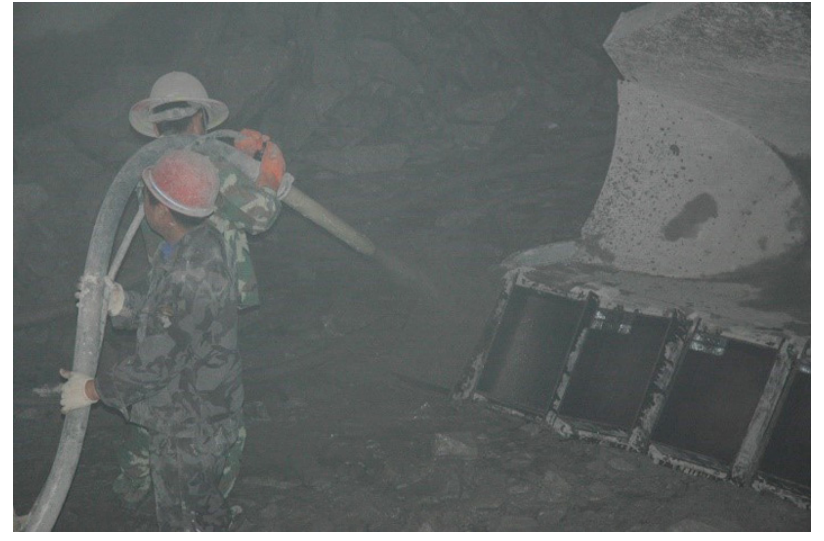

Fig. 1. Large-board spraying method

\subsection{Grouping and numbering of specimens}

Two groups of ordinary shotcrete prismoid specimens were prepared. One group included three specimens, which were subjected to rapid freeze-thaw tests. Their size was $100 \times 100 \times 400 \mathrm{~mm}$. The other group included two specimens, which were subjected to the CT scanning test. Their size was $60 \times 60 \times 100 \mathrm{~mm}$. All the specimens were numbered as DR + lot number + serial number, where DR represents the ordinary shotcrete specimens, lot number represents the batch of tests, and serial number represents the specimen number in the same batch. Similarly, two groups of shotcrete prismoid specimens mixed with the air-entraining agent were prepared. Three specimens with the size $100 \times 100 \times 400 \mathrm{~mm}$ were used for the rapid freeze-thaw tests. Two specimens with the size $60 \times 60 \times 100 \mathrm{~mm}$ were used for the CT scanning test. They were numbered DRY + lot number + serial number, where DRY represents the shotcrete specimens mixed with the air-entraining agent, and lot number and serial number are the same as above. The specimens map is shown in Figure 2.

\subsection{Experimental contents}

Three parameters of the shotcrete specimens, including (1) mass loss, (2) dynamic modulus of elasticity, and (3) ultrasonic wave velocity, were tested at an interval of 25 freeze-thaw cycles until 400 freeze-thaw cycles were completed. Thus, the degree of the deterioration of the internal structure of the shotcrete specimens mixed with the air-entraining agent and the ordinary shotcrete specimens could be determined macroscopically during the freeze-thaw cycles. X-ray CT scanning was performed at an interval of 50 freeze-thaw cycles until 200 freezethaw cycles were completed, by which the changes in the internal pore structure of the shotcrete specimens mixed with the air-entraining agent and the ordinary shotcrete specimens could be revealed microscopically. Therefore, the effect of the freeze-thaw cycles on the internal structure of the two kinds of shotcrete could be investigated in detail through combining the four tests. 


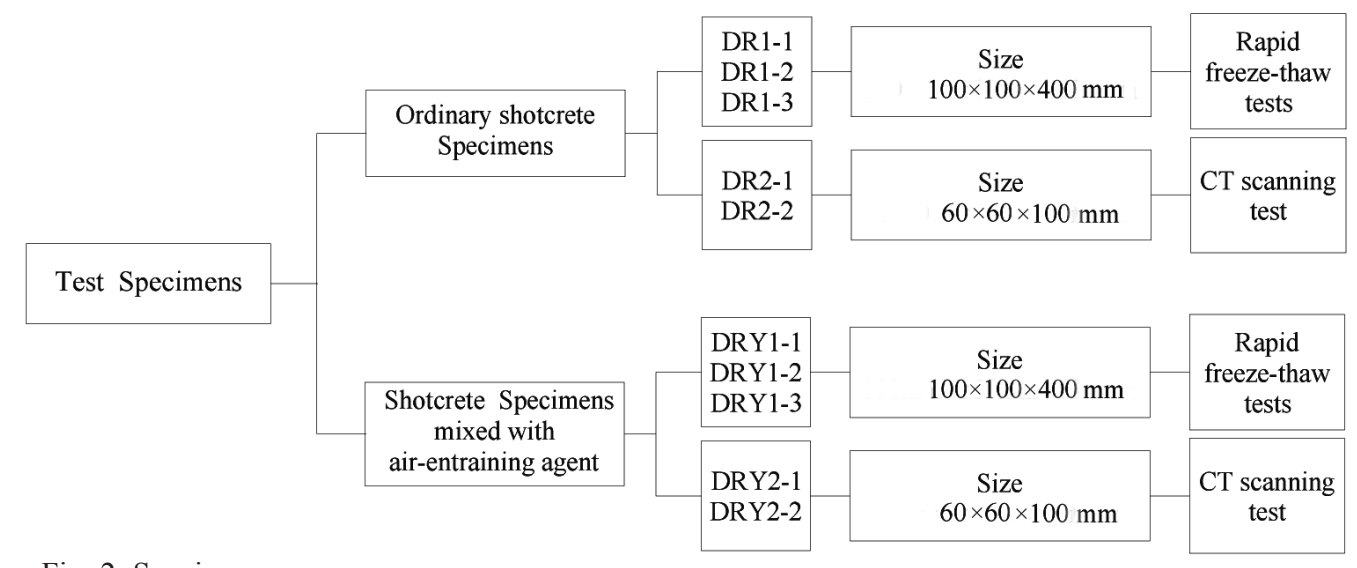

Fig. 2. Specimens map

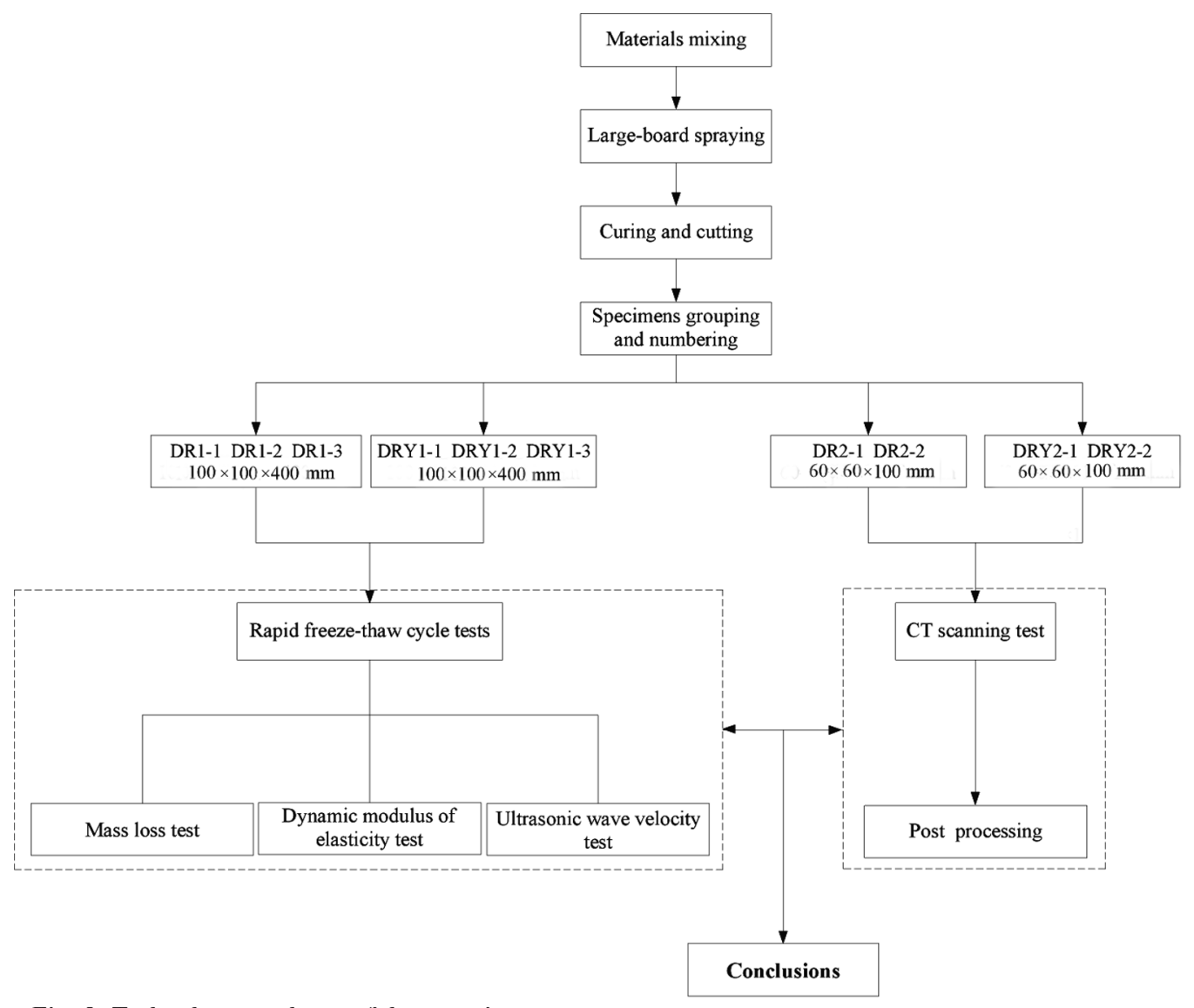

Fig. 3. Technology roadmap of the experiment

\subsection{Experimental methods and procedures}

The technology roadmap of the experiment is shown in Figure 3. The freeze-thaw cycles were conducted using an automatic rapid concrete freeze-thaw tester in the Frozen Earth Lab of Chang'an University. Each freeze-thaw cycle was completed for $4 \mathrm{~h}$ to $5 \mathrm{~h}$; the time of thawing was not less than $1 / 4$ of the whole freeze-thaw cycle to ensure the adequate thawing of the specimens. During this process, the temperature of the central part of the specimens was maintained between $-18 \pm 2{ }^{\circ} \mathrm{C}$ and $5 \pm 2{ }^{\circ} \mathrm{C}$. The specific procedures of the experiment are described in detail in ASTM C666/C666M-03 (2003).

\section{Rapid freeze-thaw cycle tests}

The mass loss, dynamic modulus of elasticity and ultrasonic wave velocity of the specimens, namely DR1-1 to DR1-3 and DRY1-1 to DRY1-3, were tested at an interval of 25 freeze-thaw cycles until 400 freeze-thaw cycles were completed. The results were recorded, and the figures were provided to analyse and compare the different effects of the freeze-thaw cycles on the damage to the internal structure of the ordinary shotcrete and the shotcrete mixed with the air-entraining agent. 


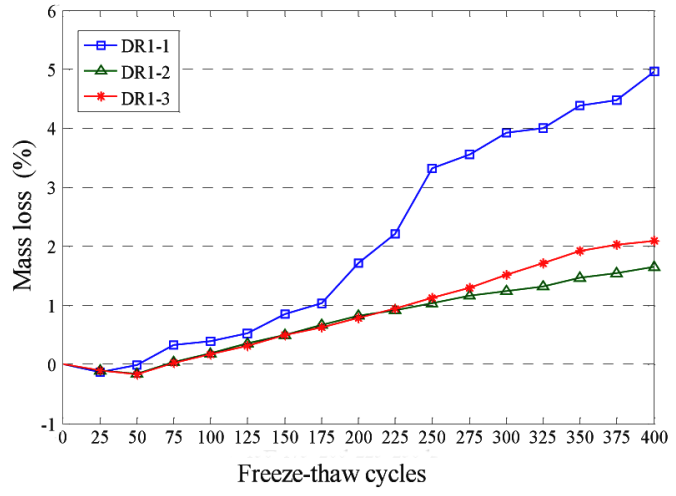

(a) Ordinary shotcrete

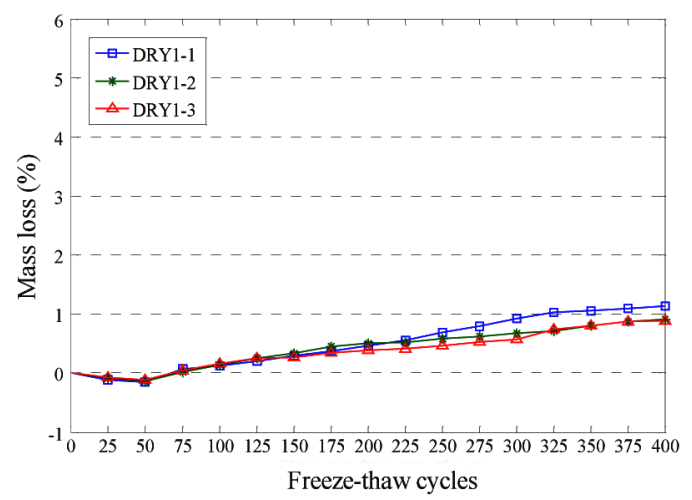

(b) Shotcrete mixed with the air-entraining agent

Fig. 4. Change in mass loss of the shotcrete specimens during the freeze-thaw cycles

\subsection{Mass loss test}

The degree of damage to shotcrete specimens during freeze-thaw cycles can be indicated directly by the mass loss of the specimens. Therefore, the mass loss is chosen as the main parameter to analyse. The changes in the mass loss of the shotcrete specimens mixed with the air-entraining agent and the ordinary shotcrete specimens, along with the freeze-thaw cycles, are shown in Figure 4.

Figure 4 shows that the mass loss of the ordinary shotcrete specimens shifted from negative to positive values between 50 and 75 freeze-thaw cycles. The mass loss of the shotcrete specimens mixed with the air-entraining agent was also negative before 75 freeze-thaw cycles were completed. In addition, before 100 freezethaw cycles were completed, the mass loss of the two kinds of shotcrete was approximate. However, after 150 freeze-thaw cycles were performed, the mass loss of the shotcrete mixed with the air-entraining agent was significantly lower than that of the ordinary shotcrete.

During the experiment, cement mortar fragmentations appeared in the freeze-thaw tester, after the ordinary shotcrete specimens underwent approximately 100 freeze-thaw cycles. However, 150 freeze-thaw cycles were required for the shotcrete specimens mixed with the air-entraining agent.

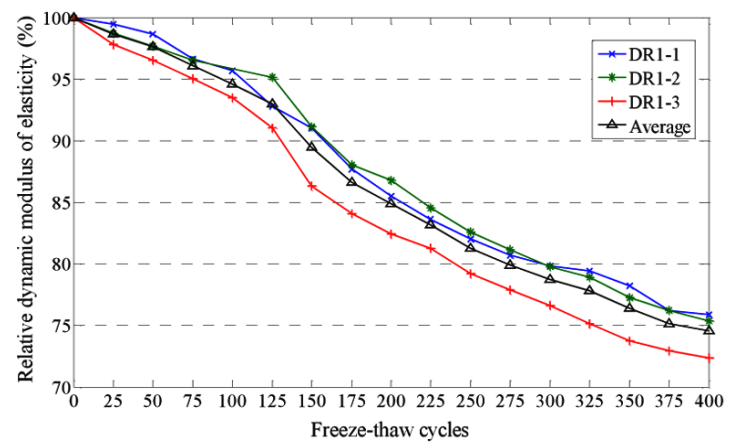

(a) Ordinary shoecrete
Therefore, before 75 freeze-thaw cycles were completed, few small pores and fine cracks formed in both kinds of shotcrete specimens. It caused that moisture content of the specimens increased after freezing and thawing, and the resulting mass loss was negative. After 100 freeze-thaw cycles were completed, the ordinary shotcrete specimens were greatly damaged as some cement mortar fragmentations appeared. The same phenomenon was observed in the shotcrete specimens mixed with the air-entraining agent after 150 freeze-thaw cycles were completed. However, the damage to the shotcrete specimens mixed with the air-entraining agent was less than that to the ordinary shotcrete specimens.

\subsection{Dynamic modulus of elasticity test}

In this test, the dynamic modulus of elasticity can be obtained through the conversion of the elastic wave propagation velocity in the shotcrete. This parameter is closely related to the density of the specimen. Therefore, the relative dynamic modulus of elasticity was used here to evaluate the degree of deterioration of the internal structure of the shotcrete specimens during the freeze-thaw cycles. The changes in the relative dynamic modulus of elasticity of the ordinary shotcrete specimens and that

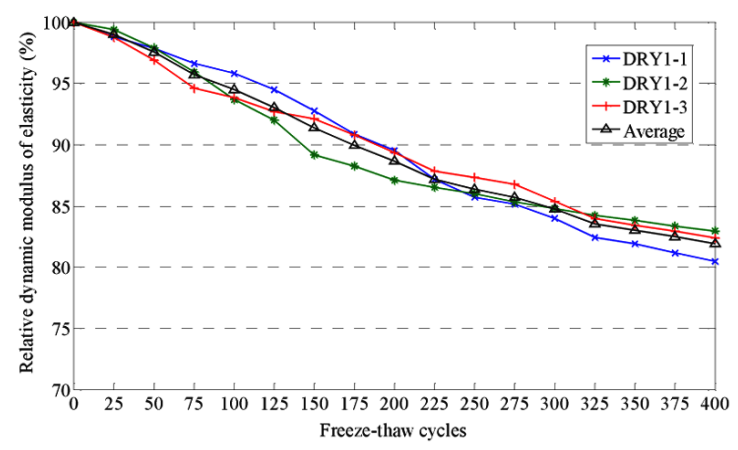

(b) Shotcrete mixed with air-entraining agent

Fig. 5. Change in relative dynamic modulus of elasticity of the shotcrete specimens during the freeze-thaw cycles 
of the shotcrete specimens mixed with the air-entraining agent, along with the freeze-thaw cycles, are shown in ren Figure 5.

Figure 5 shows that the decrease rate of the relative dynamic modulus of elasticity of the ordinary shotcrete specimens suddenly increased near the 100th freezethaw cycle. However, during the freeze-thaw cycles, the decrease rate of the shotcrete mixed with air-entraining agent specimens barely changed overall. Moreover, after 150 freeze-thaw cycles were completed, the decrease rate even dropped slightly. Therefore, after 150 freeze-thaw cycles were completed, the value of the relative dynamic modulus of elasticity of the shotcrete specimens mixed with the air-entraining agent was higher than that of the ordinary shotcrete specimens. The results of the mass loss test and the dynamic modulus of elasticity test lead to the inference that the sudden increase in the decrease rate of the dynamic modulus of elasticity of ordinary shotcrete is likely related to the occurring of cement mortar fragmentations, after 100 freeze-thaw cycles were completed. However, for the shotcrete specimens mixed with the air-entraining agent, such an effect was quite less. Thus, the deterioration of the structure of shotcrete could be reduced effectively by adding an air-entraining agent, as the number of freeze-thaw cycles increased. Moreover, the effect was more significant after 150 freeze-thaw cycles were completed and cement mortar fragmentations occurred.

\subsection{Ultrasonic wave velocity test}

In this test, the measured ultrasonic wave velocity corresponded to the propagation velocity of the ultrasonic wave in the shotcrete specimens. This parameter is correlated with the elastic property and internal structures (e.g., pores, material composition, etc.) of shotcrete. In this study, changes in ultrasonic wave velocity were mainly attributed to changes in the inner pore structure of the shotcrete specimens. The ultrasonic wave velocity decreases, when an ultrasonic wave transmits through some pores or cracks. Therefore, the relative ultrasonic wave velocity was chosen to evaluate the degree of dete-

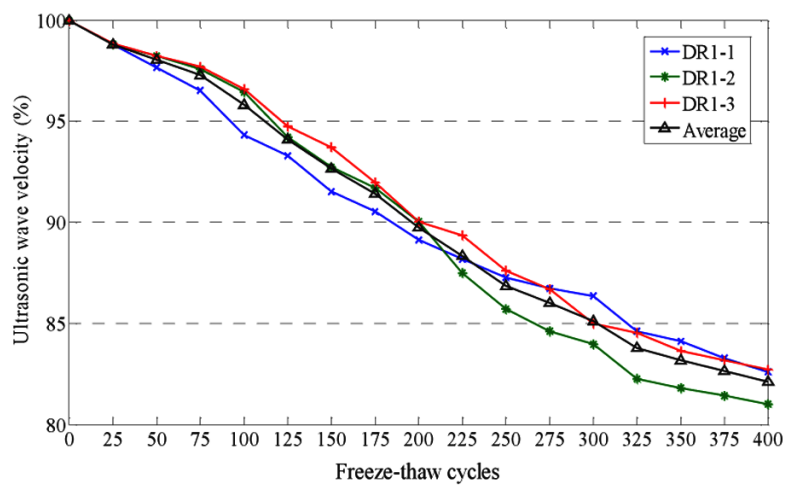

(a) Ordinary shotcrete rioration of the internal pore structure of the specimens at different numbers of freeze-thaw cycles. The changes in the relative ultrasonic wave velocity of the two groups of specimens, along with the freeze-thaw cycles, are shown in Figure 6.

Figure 6 shows that the decrease rate of the relative ultrasonic wave velocity of the ordinary shotcrete suddenly increased at approximately the 100th freeze-thaw cycle. It was also attributed to the occurring of cement mortar fragmentations. However, during the freeze-thaw cycles, the decrease rate of the dynamic modulus of elasticity of the shotcrete specimens mixed with the air-entraining agent did not increase largely, although cement mortar fragmentations appeared after 150 freeze-thaw cycles. Moreover, after 200 freeze-thaw cycles were completed, the decrease rate even dropped slightly. Therefore, the value of the relative ultrasonic wave velocity of the shotcrete specimens mixed with the air-entraining agent was higher than that of the ordinary shotcrete specimens, after 150 freeze-thaw cycles were completed. Based on the above, the deterioration of the internal pore structure of shotcrete caused by frequent freeze-thaw cycles could be effectively reduced by adding an air-entraining agent. Moreover, the effect was more significant after 150 freeze-thaw cycles were completed.

\section{Industrial CT scanning test}

\subsection{Principle of the test}

The type of Y. CT Precision S industrial CT scanner (Fig. 7) was utilised in this test to reveal the changes in the pore structure of the shotcrete specimens as the number of freeze-thaw cycles increased. It is composed of a scanning system, ray protective room, computer system, micro focus controller and power distribution box. The ray protective room, scanning system and computer system are the main components. The detected objects are scanned in the ray protective room. The scanning system is composed of a detector and ray source. The computer system is used to analyse the scanning results and to present the CT scanning results of the detected objects in

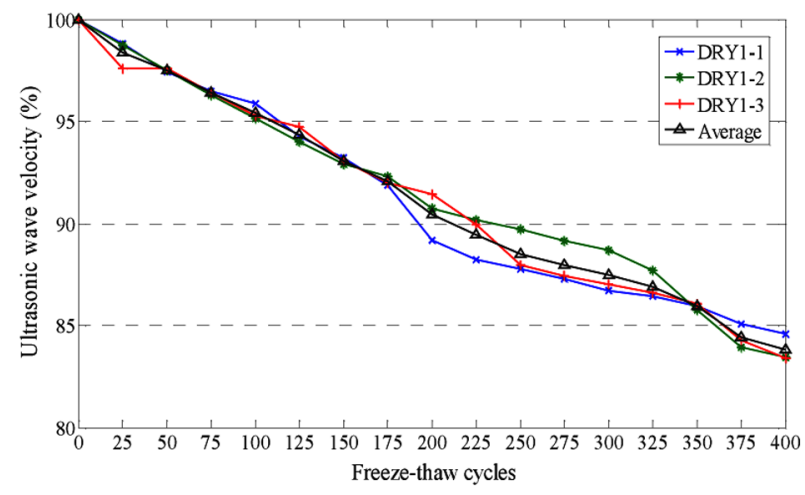

(b) Shotcrete mixed with an air-entraining agent

Fig. 6. Change in ultrasonic wave velocity of the shotcrete specimens during the freeze-thaw cycles 


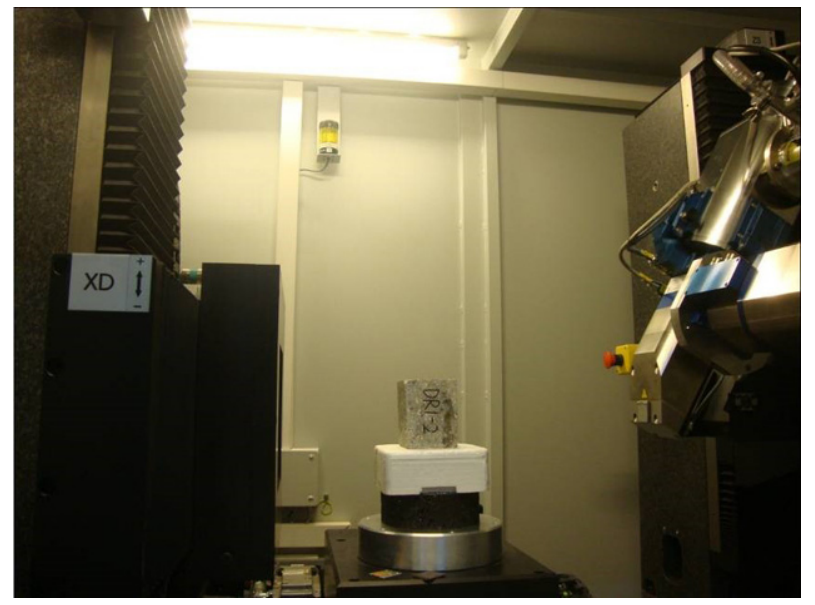

Fig. 7. Y. CT Precision S industrial CT scanner

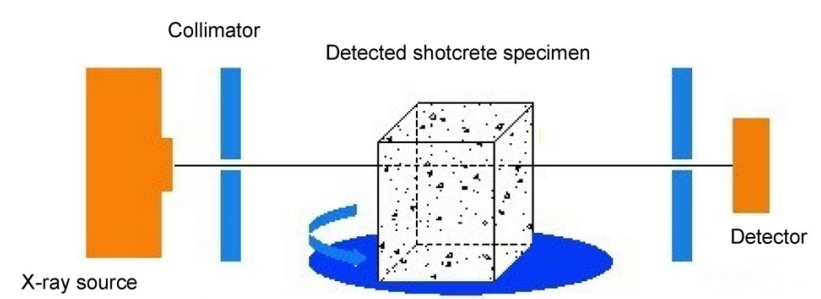

Fig. 8. X-ray CT scanning system

the form of images. A sketch of the X-ray CT scanning system is shown in Figure 8. The precision of the CT scanning system is $0.01 \mathrm{~mm}^{2}$. Therefore, the pores with an area of $\geq 0.01 \mathrm{~mm}^{2}$ can be captured by the CT scanning system inside the shotcrete specimens. These pores $\left(\geq 0.01 \mathrm{~mm}^{2}\right)$ do not include the majority of bubbles in the shotcrete mixed with the air-entraining agent, and most of them are detrimental to the freeze-thaw durability of shocrete.

The size of the specimen and the specific division of the test cross-sections are shown in Figure 9. Scanning was performed when the specimens DR2-1, DRY2-1, DR2-2 and DRY2-2 underwent 0, 50, 100, 150 and 200 freeze-thaw cycles, respectively. After scanning, the results were visually reconstructed using the Software VG Studio MAX 2.0 in the CT computer system to obtain the CT image of the specified test cross-section. The CT image was then imported into the Software Image-Pro Plus and was processed. Through the processing, the identified pores were marked, and the area of each pore was

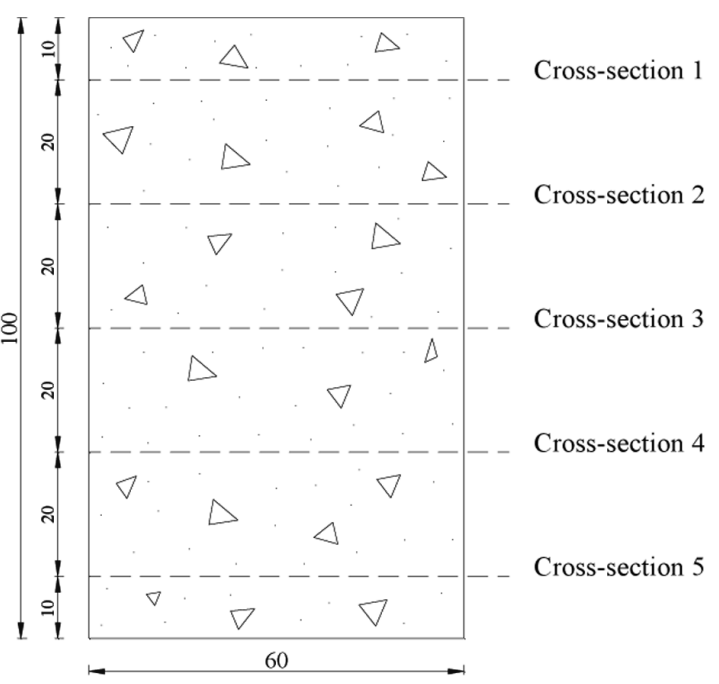

Fig. 9. Division of scanning cross-sections (unit: $\mathrm{mm}$ )

extracted. The test results were analysed and compared to reveal the different effects of freeze-thaw cycles on the internal pore structure of the ordinary shotcrete and the shotcrete mixed with the air-entraining agent.

\subsection{CT scanning results}

The CT images of the test cross-sections were obtained after different numbers of freeze-thaw cycles through the process of the CT computer system. Given that the characteristics of the CT images of the two ordinary shotcrete specimens, DR2-1 and DR2-2, were similar during the freeze-thaw cycles, only the images of the former were presented as an example for analysis here. Similarly, for the specimens of DRY2-1 and DRY2-2, only the images of the former were presented here for analysis.

Figures 10 and 11 show the CT images of each cross-section in DR2-1 and DRY2-1, respectively, before the freeze-thaw cycles were conducted. In Figures 10 and 11 , small pores, and even a few large pores, were presented regardless of the type of shotcrete. Moreover, the number of the pores in the ordinary shotcrete was larger than that in the shotcrete mixed with the air-entraining agent.

The CT images of each cross-section in DR2-1 and DRY2-1 were processed in Image-Pro Plus, after the specimens underwent $0,50,100,150$ and 200 freezethaw cycles. After the process, the marked CT images were available (Figs 12 and 13). The red marks in the images represent the pores and cracks in the cross-

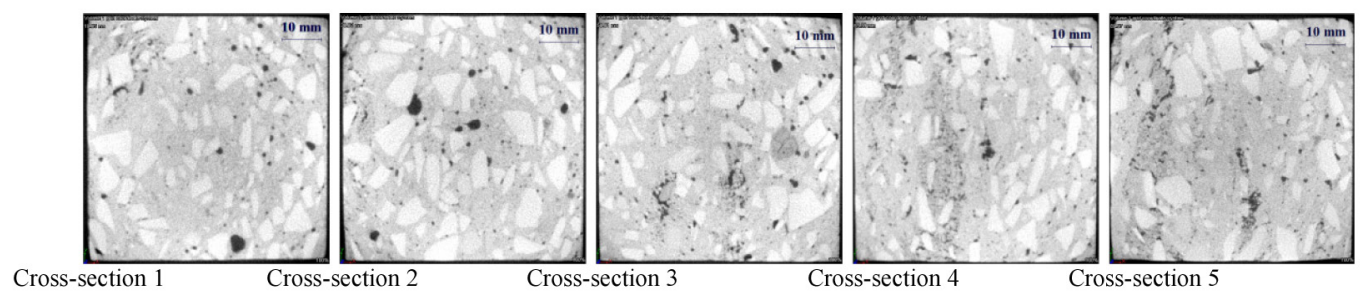

Fig. 10. CT images of each cross-section in DR2-1 before freeze-thaw cycles were performed 


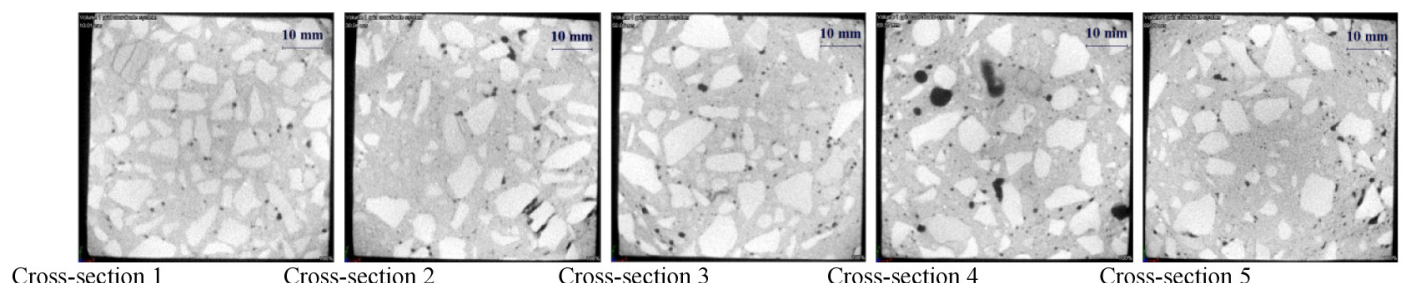

Fig. 11. CT images of each cross-section in DRY2-1 before freeze-thaw cycles were performed

section. Figures 12 and 13 were analysed and compared, and the results showed that the number of small pores in the specific cross-section changed greatly as the number of freeze-thaw cycles increased. However, the number of large pores changed barely. Within 200 freeze-thaw cy- cles, no large and evident cracks with a width of $\geq 0.1 \mathrm{~mm}$ was captured inside the specimens, except for few adjacent pores interconnecting with and some fractures appearing on the edge of the specimens.

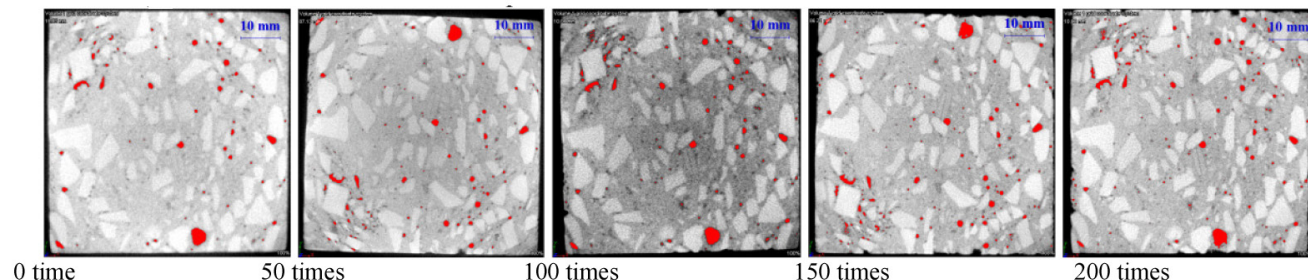

(a) Cross-section 1

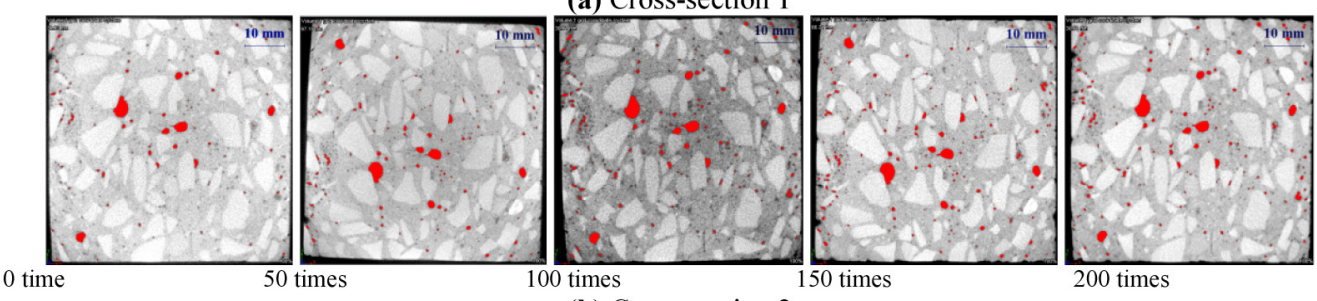

(b) Cross-section 2

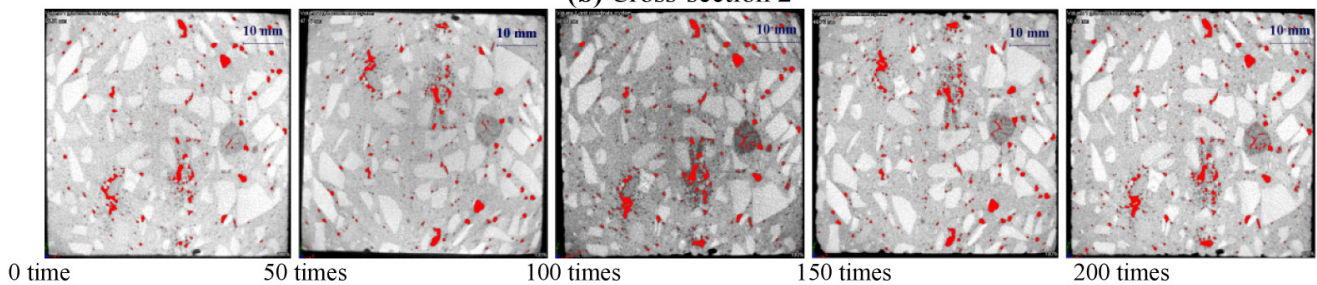

(c) Cross-section 3

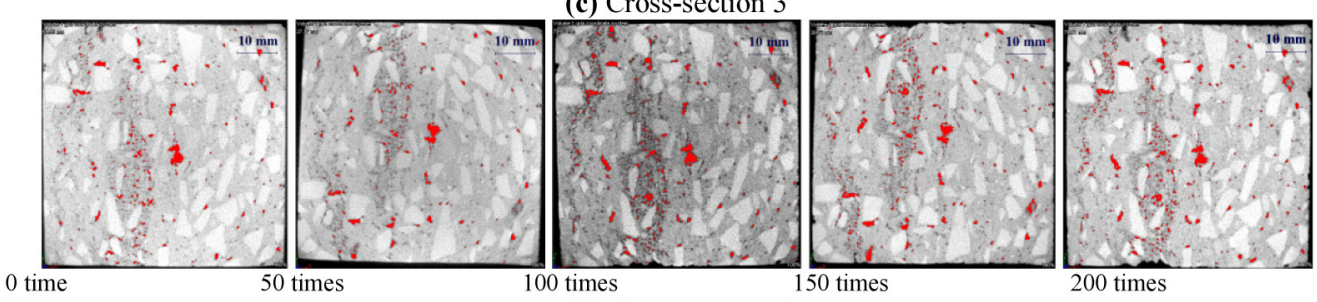

(d) Cross-section 4
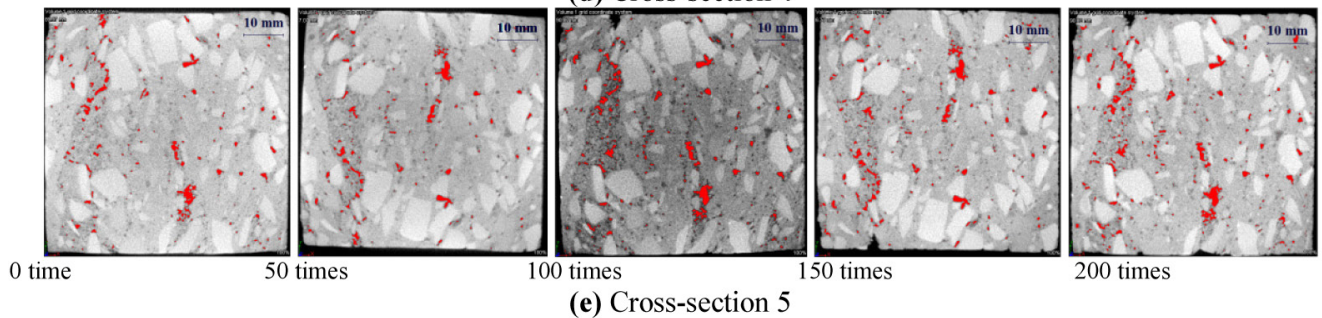

(e) Cross-section 5

Fig. 12. Changes in the pores of each cross-section in DR2-1 as the number of freeze-thaw cycles increased 

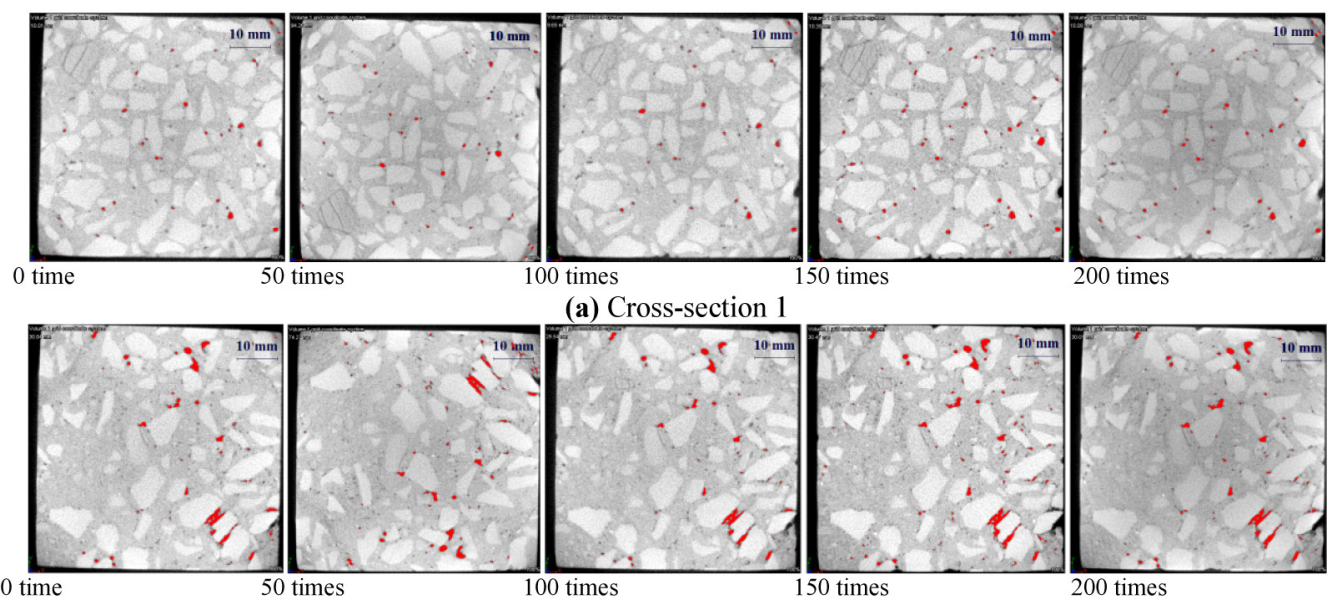

(b) Cross-section 2

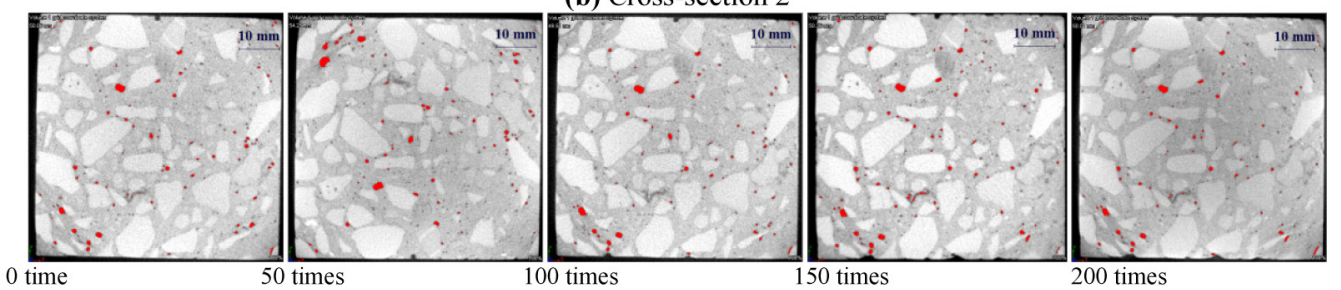

(c) Cross-section 3

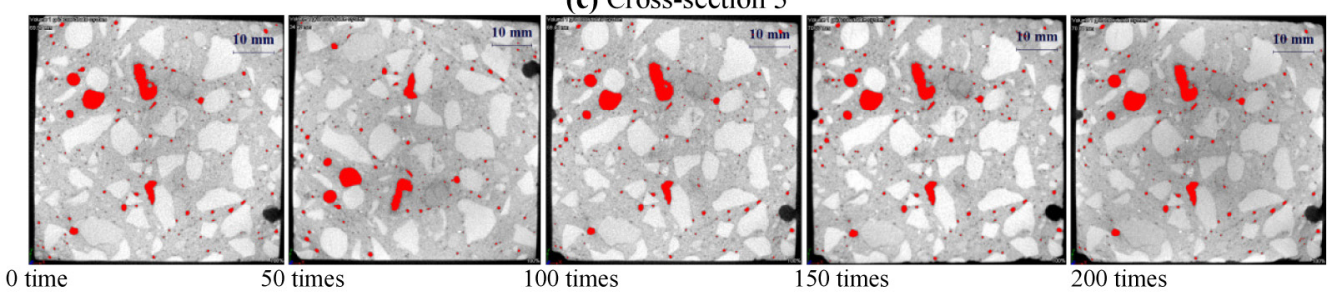

(d) Cross-section 4

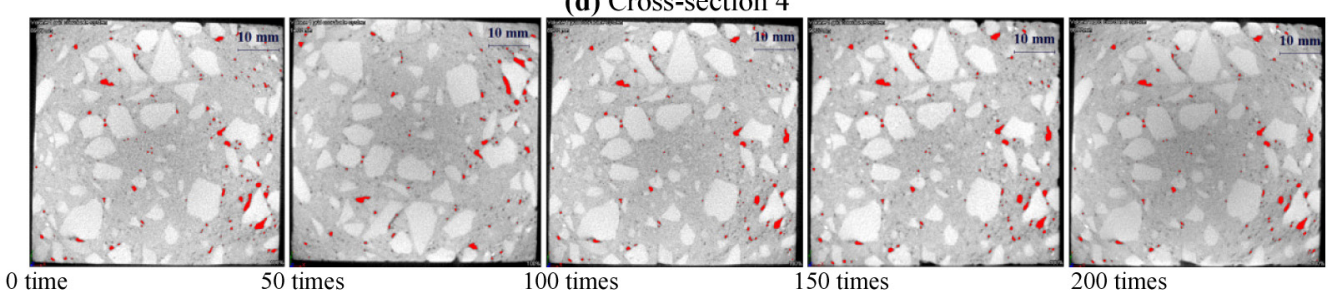

(e) Cross-section 5

Fig. 13. Changes in the pores of each cross-section in DRY2-1 as the number of freeze-thaw cycles increased

\subsection{Analysis of the $\mathrm{CT}$ scanning results}

The area of each pore (i.e., the red mark in the processed CT images) in the specific cross-section was determined using Image-Pro Plus. The number of the pores in the cross-section was counted. The results were statistically analysed. Tables 1 and 2 present the number of pores in certain area intervals, after the two groups of specimens underwent different numbers of freeze-thaw cycles.

Tables 1 and 2 show that the internal pores in the shotcrete specimens mixed with the air-entraining agent and the ordinary shotcrete specimens mainly concentrated between 0.01 and $1.00 \mathrm{~mm}^{2}$ before the freeze-thaw cycles were performed. This excludes the pores or bubbles with an area of $<0.01 \mathrm{~mm}^{2}$ because of the precision of the CT scanning system. The pores with an area of $0.01-$ $1.00 \mathrm{~mm}^{2}$ occupied $93.3 \%$ and $91.3 \%$ of all the pores $\left(\geq 0.01 \mathrm{~mm}^{2}\right)$ in the ordinary shotcrete specimens and the shotcrete specimens mixed with the air-entraining agent, respectively. In addition, in this area interval, the number of pores in the ordinary shotcrete specimens was significantly larger than that in the shotcrete specimens mixed with the air-entraining agent.

As the number of freeze-thaw cycles increased, the number of the pores in the shotcrete increased. The increase was mainly concentrated in the pores with an area between 0.01 and $0.50 \mathrm{~mm}^{2}$. The correlation between the number of the small pores $\left(0.01 \mathrm{~mm}^{2}\right.$ to $\left.0.50 \mathrm{~mm}^{2}\right)$ in the two groups of specimens and the number of freeze-thaw cycles is shown in Figure 14. The number of the small pores $\left(0.01 \mathrm{~mm}^{2}\right.$ to $\left.0.50 \mathrm{~mm}^{2}\right)$ significantly increased when the ordinary shotcrete specimens underwent 100 freeze-thaw cycles. A similar phenomenon was observed 
Table 1. Pore size distributions in the ordinary shotcrete specimens after different numbers of freeze-thaw cycles

\begin{tabular}{|c|c|c|c|c|c|c|}
\hline \multirow{2}{*}{$\begin{array}{l}\text { Specimen } \\
\text { No. }\end{array}$} & \multirow{2}{*}{$\begin{array}{c}\text { Number of freeze-thaw } \\
\text { cycles }\end{array}$} & \multicolumn{5}{|c|}{ Area interval } \\
\hline & & $\begin{array}{c}0.01-0.50 \\
\left(\mathrm{~mm}^{2}\right)\end{array}$ & $\begin{array}{c}0.50-1.00 \\
\left(\mathrm{~mm}^{2}\right)\end{array}$ & $\begin{array}{c}1.00-1.50 \\
\left(\mathrm{~mm}^{2}\right)\end{array}$ & $\begin{array}{c}1.50-2.00 \\
\left(\mathrm{~mm}^{2}\right)\end{array}$ & $\begin{array}{l}>2.00 \\
\left(\mathrm{~mm}^{2}\right)\end{array}$ \\
\hline \multirow{5}{*}{ DR2-1 } & 0 & 700 & 79 & 20 & 12 & 24 \\
\hline & 50 & 601 & 64 & 18 & 12 & 22 \\
\hline & 100 & 818 & 73 & 22 & 15 & 27 \\
\hline & 150 & 927 & 77 & 28 & 15 & 29 \\
\hline & 200 & 1117 & 78 & 31 & 14 & 31 \\
\hline \multirow{5}{*}{ DR2-2 } & 0 & 507 & 56 & 19 & 7 & 15 \\
\hline & 50 & 527 & 39 & 19 & 5 & 14 \\
\hline & 100 & 582 & 56 & 18 & 8 & 18 \\
\hline & 150 & 880 & 73 & 20 & 10 & 18 \\
\hline & 200 & 752 & 57 & 21 & 9 & 18 \\
\hline
\end{tabular}

Table 2. Pore size distributions in the shotcrete specimens mixed with the air-entraining agent after different numbers of freeze-thaw cycles

\begin{tabular}{|c|c|c|c|c|c|c|}
\hline \multirow{2}{*}{$\begin{array}{l}\text { Specimen } \\
\text { No. }\end{array}$} & \multirow{2}{*}{$\begin{array}{c}\text { Number of freeze-thaw } \\
\text { cycles }\end{array}$} & \multicolumn{5}{|c|}{ Area interval } \\
\hline & & $\begin{array}{c}0.01-0.50 \\
\left(\mathrm{~mm}^{2}\right)\end{array}$ & $\begin{array}{c}0.50-1.00 \\
\left(\mathrm{~mm}^{2}\right)\end{array}$ & $\begin{array}{c}1.00-1.50 \\
\left(\mathrm{~mm}^{2}\right)\end{array}$ & $\begin{array}{c}1.50-2.00 \\
\left(\mathrm{~mm}^{2}\right)\end{array}$ & $\begin{array}{l}>2.00 \\
\left(\mathrm{~mm}^{2}\right)\end{array}$ \\
\hline \multirow{5}{*}{$\begin{array}{l}\text { DRY } \\
2-1\end{array}$} & 0 & 294 & 39 & 11 & 8 & 15 \\
\hline & 50 & 326 & 36 & 11 & 6 & 16 \\
\hline & 100 & 331 & 36 & 9 & 6 & 17 \\
\hline & 150 & 382 & 43 & 13 & 6 & 21 \\
\hline & 200 & 379 & 36 & 8 & 9 & 18 \\
\hline \multirow{5}{*}{$\begin{array}{l}\text { DRY } \\
2-2\end{array}$} & 0 & 385 & 42 & 11 & 6 & 21 \\
\hline & 50 & 396 & 49 & 6 & 6 & 22 \\
\hline & 100 & 398 & 33 & 10 & 7 & 19 \\
\hline & 150 & 464 & 57 & 6 & 7 & 23 \\
\hline & 200 & 369 & 42 & 7 & 11 & 18 \\
\hline
\end{tabular}

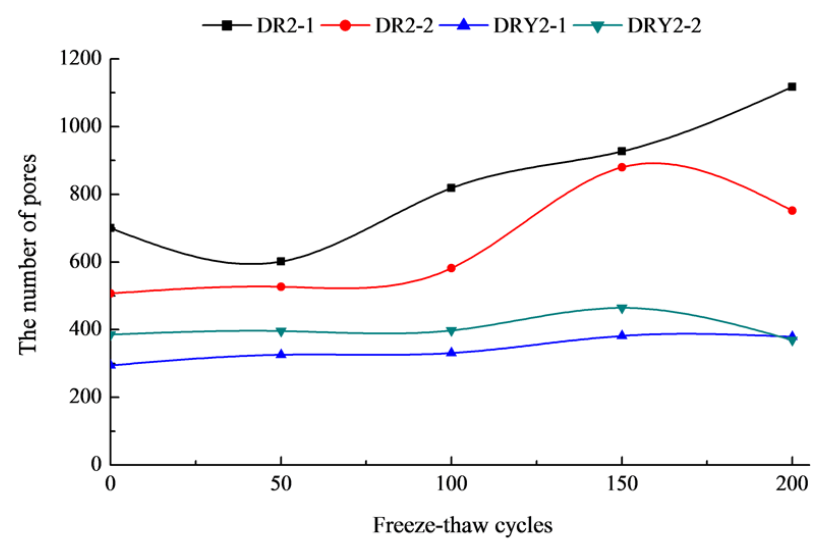

Fig. 14. Changes in the number of the pores $\left(0.01 \mathrm{~mm}^{2}\right.$ to $0.50 \mathrm{~mm}^{2}$ ) as the number of freeze-thaw cycles increased in the shotcrete specimens mixed with the air-entraining agent when they underwent 150 freeze-thaw cycles, but this increase was much smaller compared with that in ordinary shotcrete specimens. Similarly, after 150 freeze-thaw cycles were completed, the number of the pores $\left(0.01 \mathrm{~mm}^{2}\right.$ to $\left.0.50 \mathrm{~mm}^{2}\right)$ in the shotcrete specimens mixed with the air-entraining agent increased by a much smaller extent than that in the ordinary shotcrete specimens.

Based on the findings of the rapid freeze-thaw cycle tests, cement mortar fragmentations appeared when the ordinary shotcrete specimens underwent 100 freezethaw cycles. The number of small pores $\left(0.01 \mathrm{~mm}^{2}\right.$ to $0.50 \mathrm{~mm}^{2}$ ) in the specimens increased largely and suddenly. Therefore, at a macroscopic level, the decrease rate of the relative dynamic modulus of elasticity and the relative ultrasonic wave velocity of the ordinary shotcrete increased significantly after 100 freeze-thaw cycles. Similarly, when the shotcrete specimens mixed with the air-entraining agent underwent 150 freeze-thaw cycles, 
cement mortar fragmentations appeared. The number of the pores $\left(0.01 \mathrm{~mm}^{2}\right.$ to $\left.0.50 \mathrm{~mm}^{2}\right)$ also had a larger increase than the previous. However, the increment was much smaller than that of the ordinary shotcrete. At a macroscopic level, the decrease rate of the relative dynamic modulus of elasticity and the relative ultrasonic wave velocity of the shotcrete mixed with the air-entraining agent barely increased and even dropped slightly. Therefore, after 150 freeze-thaw cycles were completed, the relative dynamic modulus of elasticity and the relative ultrasonic wave velocity of the shotcrete mixed with the air-entraining agent were higher than those of the ordinary shotcrete. The mass loss of the shotcrete mixed with the air-entraining agent was also much lower than that of the ordinary shotcrete after 150 freeze-thaw cycles. The above findings suggest that the addition of an air-entraining agent could effectively prevent the development of small pores $\left(0.01 \mathrm{~mm}^{2}\right.$ to $\left.0.50 \mathrm{~m} \mathrm{~mm}^{2}\right)$ in shotcrete and therefore improve the freeze-thaw durability during freeze-thaw cycles, especially after 150 freeze-thaw cycles were completed and cement mortar fragmentations appeared.

\section{Conclusions}

In this study, the CT scanning results of the pore structure of $\mathrm{C} 25$ ordinary shotcrete specimens and that of shotcrete specimens mixed with the air-entraining agent were analysed and compared after different numbers of freezethaw cycles. Coupled with the results of the macroscopic tests, including mass loss, dynamic modulus of elasticity and ultrasonic wave velocity tests, the following conclusions are obtained:

1. After shotcrete hardens and forms, a certain number of pores are produced inside the shotcrete, regardless of the type of shotcrete (i.e., shotcrete mixed with the air-entraining agent and ordinary shotcrete). The pores are mainly concentrated between 0.01 and $1.00 \mathrm{~mm}^{2}$ (except for the pores or bubbles of $<0.01 \mathrm{~mm}^{2}$ because of the precision of the CT scanning system). And, the pores $\left(0.01 \mathrm{~mm}^{2}\right.$ to $1.00 \mathrm{~mm}^{2}$ ) account for more than $90 \%$ of the total pores $\left(\geq 0.01 \mathrm{~mm}^{2}\right)$ in the specimens. In addition, in this area range, the number of the small pores in the ordinary shotcrete is much larger than that in the shotcrete mixed with the air-entraining agent. Therefore, the addition of an air-entraining agent can effectively reduce the initial damage to shotcrete.

2. As the number of freeze-thaw cycles increased, some changes occur in the internal pore structure of both kinds of shotcrete. During the first few freezethaw cycles, just few small pores occur and develop in the specimens, which causes that the moisture content of both kinds of shotcrete specimens increases slightly after freezing and thawing. Therefore, the mass loss is negative before approximately 75 freeze-thaw cycles.
3. After 100 and 150 freeze-thaw cycles are completed, cement mortar fragmentations appear in ordinary shotcrete and shotcrete mixed with the air-entraining agent, respectively. The number of small pores in both kinds of shotcrete increases significantly. And, the pores are mainly concentrated between 0.01 and $0.50 \mathrm{~mm}^{2}$. However, the increment of shotcrete mixed with the air-entraining agent is much smaller than that of ordinary shotcrete. Therefore, the deterioration of the internal pore structure of shotcrete mixed with the air-entraining agent is less than that of ordinary shotcrete after 150 freeze-thaw cycles. This finding is also verified by the results of the macroscopic rapid freeze-thaw cycles tests. Based on the above, the number of small pores $\left(0.01 \mathrm{~mm}^{2}\right.$ to $\left.0.50 \mathrm{~mm}^{2}\right)$ in ordinary shotcrete increases significantly after cement mortar fragmentations appeared. However, the addition of an air-entraining agent not only defers the appearing of cement mortar fragmentations, but also prevents the development of small pores $\left(0.01 \mathrm{~mm}^{2}\right.$ to $\left.0.50 \mathrm{~mm}^{2}\right)$, which effectively improves the freeze-thaw durability of shotcrete.

\section{Acknowledgements}

This work was supported by the National Natural Science Foundation of China (Grant Nos. 51078040, 51278063, 51408054 and 51108034), the State Key Development Program for Basic Research of China (Grant No. 2013CB036003), the Chang Jiang Scholars Program (No. T2014214), the National Science and Technology Support Program (Grant No. 2011BAE27B04), the Research Project of Shannxi Provincial Transport Department (Grant No. 13-14K), the Science and Technology Co-ordinating Innovative Engineering Project of Shanxi Province (Grant No. 2014KTCG01-02) and the Fundamental Research Funds for the Central Universities (Grant Nos. 2013G1281075 and 2013G2211001).

\section{References}

ASTM C666/C666M-03. Standard test method for resistance of concrete to rapid freezing and thawing. ASTM, USA, 2003.

Chatterji, S. 2003. Freezing of air-entrained cement-based materials and specific actions of air-entraining agents, Cement and Concrete Composites 25(7): 759-765. https://doi.org/10.1016/S0958-9465(02)00099-9

Chen, J. X.; Zhao, X. Z.; Luo, Y. B.; Deng, X. H.; Liu, Q. 2014. Investigating freeze-proof durability of $\mathrm{C} 25$ shotcrete, Construction and Building Materials 61: 33-40. https://doi.org/10.1016/j.conbuildmat.2014.02.077

Chung, S. Y.; Han, T. S.; Kim, S. Y. 2015. Reconstruction and evaluation of the air permeability of a cement paste specimen with a void distribution gradient using CT images and numerical methods, Construction and Building Materials 87: $45-53$.

https://doi.org/10.1016/j.conbuildmat.2015.03.103

GB/T 50086-2001. Specifications for bolt-shotcrete support. Chinese standard, 2001. 
GB175-2007. Common portland concrete. Chinese standard, 2007.

JTG/TF50-2011. Technical specification for construction of highway bridge and culvert. Chinese standard, 2011.

Lomboy, G.; Wang, K. J. 2009. Effects of strength, permeability, and air void parameters on freezing-thawing resistance of concrete with and without air entrainment, Journal of ASTM International 6(10): 1-14.

Molero, M.; Aparicio, S.; Al-Assadi, G.; Casati, M. J.; Hernández, M. G.; Anaya, J. J. 2012. Evaluation of freeze-thaw damage in concrete by ultrasonic imaging, NDT \& E International 52: 86-94. https://doi.org/10.1016/j.ndteint.2012.05.004

Ranz, J.; Aparicio, S.; Romero, H.; Casati, M. J.; Molero, M.; González, M. 2014. Monitoring of freeze-thaw cycles in concrete using embedded sensors and ultrasonic imaging, Sensors 14(2): 2280-2304. https://doi.org/10.3390/s140202280

Savaş, E. 2014. X-ray computed tomography and fractal analysis for the evaluation of segregation resistance, strength response and accelerated corrosion behaviour of self-compacting lightweight concrete, Construction and Building Materials 61(30): 10-17.
Suzuki, T.; Ohtsu, M.; Shigeishi, M. 2007. Relative damage evaluation of concrete in aroad bridge by $\mathrm{AE}$ rate-process analysis, Materials and Structures 40: 221-227. https://doi.org/10.1617/s11527-006-9133-9

Suzuki, T.; Ogata, H.; Takada, R.; Aoki, M.; Ohtsu, M. 2010. Use of acoustic emission and X-ray computed tomography for damage evaluation of freeze-thawed concrete, Construction and Building Materials 24(12): 2347-2352. https://doi.org/10.1016/j.conbuildmat.2010.05.005

Yi, X. W.; Ma, G. W.; Fourie, A. 2015. Compressive behaviour of fibre-reinforced cemented paste backfill, Geotextiles and Geomembranes 43(3): 207-215. https://doi.org/10.1016/j.geotexmem.2015.03.003

Yuan, J.; Liu, Y.; Tan, Z.; Zhang, B. 2016. Investigating the failure process of concrete under the coupled actions between sulfate attack and drying-wetting cycles by using X-ray CT, Construction and Building Materials 108: 129-138. https://doi.org/10.1016/j.conbuildmat.2016.01.040

Zofka, A.; Paliukaitè, M.; Vaitkus, A.; Maliszewska, D.; Josen, R.; Bernier, A. 2014. Laboratory study on the influence of casting on properties of ultra-high performance fibre reinforced concrete (UHPFRC) specimens, Journal of Civil Engineering and Management 20(3): 380-388. https://doi.org/10.3846/13923730.2014.913680

Jianxun CHEN. PhD, Professor at the Institute of Geotechnical and Tunnel Engineering in School of Highway, Chang'an University, Xi'an, China. He got his Bachelor's and Master's degrees from Chang'an University, and his Doctor's degree from Beijing Jiaotong University. He was selected into the Chang Jiang Scholars Program in 2015. His research interests include lining structure design and construction technology of loess tunnel, freezing damage prevention in cold regions tunnel, weak surrounding rock stability theory and deformation control technology.

Pengyu ZHAO. PhD student at the Institute of Geotechnical and Tunnel Engineering in School of Highway, Chang'an University, Xi'an, China. He received his Master's degree from Chang'an University. His major research interest is the mechanism of tunnel freezing damage and control technology.

Yanbin LUO. PhD, Associate Professor at the Institute of Geotechnical and Tunnel Engineering in School of Highway, Chang'an University, Xi'an, China. He received his Doctor's degree from Beijing Jiaotong University. His research interests include lining structure design and construction technology of loess tunnel, freezing damage prevention in cold regions tunnel, long tunnel ventilation and operation.

Xianghui DENG. PhD, Associate Professor at the School of Civil and Architecture Engineering in Xi'an Technological University, China. He got his Doctor's degree from Xi' an University of Technology, China. His research interests include optimization of tunnel support parameters and construction technology, seepage characteristics of rock mass.

Qin LIU. PhD, Lecturer at the School of Civil Engineering, Chang'an University, Xi'an, China. He received his Doctor's degree from Shandong University, China. His major research interest is weak surrounding rock stability theory of tunnel and deformation control technology. 